\title{
BMJ
}

\section{Making decisions for people with dementia who lack capacity: qualitative study of family carers in UK}

\author{
Gill Livingston, professor of older people's mental health, ${ }^{1}$ Gerard Leavey, director of research, ${ }^{2}$ Monica \\ Manela, research doctor, ${ }^{1}$ Deborah Livingston, research fellow, ${ }^{1}$ Greta Rait, senior clinical scientist, ${ }^{3}$ Elizabeth \\ Sampson, senior lecturer in psychiatric and supportive care of the elderly, ${ }^{1}$ Shilpa Bavishi, research assistant, ${ }^{1}$ \\ Khodayar Shahriyarmolki, research assistant, ${ }^{1}$ Claudia Cooper, senior clinical lecturer in old age psychiatry
}

\begin{abstract}
'Department of Mental Health Sciences, University College London, London W1W 7EJ

${ }^{2}$ Northern Ireland Association for Mental Health (NIAMH) and University of Ulster, Belfast BT7 1HE

${ }^{3}$ MRC General Practice Research Framework, London NW1 2ND
\end{abstract}

Correspondence to: G Livingston g.livingston@ucl.ac.uk

Cite this as: BMJ 2010;341:C4184 doi:10.1136/bmj.c4184

\section{ABSTRACT}

Objective To identify common difficult decisions made by family carers on behalf of people with dementia, and facilitators of and barriers to such decisions, in order to produce information for family carers about overcoming barriers.

Design Qualitative study to delineate decision areas through focus groups and complexity of decision making in individual interviews.

Setting Community settings in London.

Participants 43 family carers of people with dementia in focus groups and 46 carers who had already made such decisions in individual interviews.

Results Family carers identified five core problematic areas of decision making: accessing dementia related health and social services; care homes; legal-financial matters; non-dementia related health care; and making plans for the person with dementia if the carer became too ill to care for them. They highlighted the difficulties in making proxy decisions, especially against active resistance, and their altered role of patient manager while still a family member. Families devised strategies to gain agreement in order to ensure that the person with dementia retained dignity.

Conclusions The following strategies helped with implementation of decisions: introducing change slowly; organising legal changes for the carer as well as the patient; involving a professional to persuade the patient to accept services; and emphasising that services optimised, not impeded, independence. To access services, carers made patients' general practice appointments, accompanied them to the surgery, pointed out symptoms, gained permission to receive confidential information, asked for referral to specialist services, and used professionals' authority to gain patients' agreement. End of life decisions were particularly difficult. They were helped by knowledge of the person with dementia's previous views, clear prognostic information, and family support. Information sheets to help carers to overcome barriers to proxy decision making have been developed; their impact in practice has yet to be evaluated.

\section{INTRODUCTION}

As the population ages, a large and increasing number of people are caring for a relative or friend with dementia. ${ }^{1}$ Decisions often have to be made on behalf of people without capacity, which includes many people with dementia, and relatives often do this, either by themselves or by acting as an advocate and giving advice to professionals for the person for whom they care. They report major barriers to doing so, including difficulties in deciding what to do and the family member experiencing distress in making a decision. ${ }^{2}$ Other obstacles to proxy decision making include having insufficient information about the possible alternatives and their effect. ${ }^{23}$ In addition, lack of emotional support for families of people with early dementia who still have capacity acts as a barrier to the difficult discussion of future care options, including placement in residential institutions with 24 hour care (care homes), and makes reaching a decision more difficult. ${ }^{45}$ Decision making will differ according to previous experiences, education, and social and cultural background. ${ }^{6}$ Some people seek information, whereas others do not. ${ }^{7}$ All are facilitated in making decisions if they have access to good information and support. ${ }^{8}$

Some countries have legislation about proxy decision making, enabling family carers to make decisions on behalf of people without capacity, but this is not universally the case, and legislation differs. ${ }^{59}$ In some countries, including the United Kingdom, mental capacity legislation means that proxy decision making by family members is likely to be more broadly used in future. In the UK, if a person lacks capacity to make their own medical or social decisions, the Mental Capacity Act mandates that (except when a valid advanced directive is in place) a relative who has been given lasting power of attorney makes such decisions. If there is no lasting power of attorney, the closest relative must be consulted and his or her views only disregarded for a very good reason, such as if they do not seem to be in the patient's best interest or are impossible. Relatives therefore have a high level of involvement in decision making, and this heightens the need for information about barriers and facilitators 
Table 1|Sociodemographic characteristics of family carers and recipients of care. Values are numbers (percentages) unless stated otherwise

\begin{tabular}{|c|c|c|}
\hline & $\begin{array}{l}\text { Individual interviewees } \\
\qquad(\mathrm{n}=46)\end{array}$ & $\begin{array}{l}\text { Focus group participants } \\
\qquad(n=43)\end{array}$ \\
\hline \multicolumn{3}{|l|}{ Carers } \\
\hline Mean (SD) age & $62(13.2)$ & $64(12.3)$ \\
\hline Female sex & $32(70)$ & $31(72)$ \\
\hline \multicolumn{3}{|l|}{ Marital status: } \\
\hline Married/living as couple & $29(63)$ & $30(70)$ \\
\hline Single & 7 (15) & $5(12)$ \\
\hline Widowed & $6(13)$ & $6(14)$ \\
\hline Divorced & $4(9)$ & $2(5)$ \\
\hline \multicolumn{3}{|l|}{ Relationship to care recipient: } \\
\hline Spouse & $22(48)$ & $25(58)$ \\
\hline Child & $19(41)$ & $12(28)$ \\
\hline Other (including four friends) & $5(11)$ & $6(14)$ \\
\hline \multicolumn{3}{|l|}{ Ethnicity: } \\
\hline White UK & $29(63)$ & $32(74)$ \\
\hline White other & $4(9)$ & $5(12)$ \\
\hline Black & $4(9)$ & $3(7)$ \\
\hline Asian & $4(9)$ & $1(2)$ \\
\hline Other & $5(11)$ & $2(5)$ \\
\hline \multicolumn{3}{|l|}{ Level of education: } \\
\hline No qualification & $10(22)$ & $9(21)$ \\
\hline Secondary & $16(35)$ & $15(35)$ \\
\hline Tertiary & $20(43)$ & $19(44)$ \\
\hline \multicolumn{3}{|l|}{ Religion: } \\
\hline Protestant & $17(37)$ & $8(19)$ \\
\hline Catholic & $8(17)$ & $2(5)$ \\
\hline Other Christian & $6(13)$ & $4(9)$ \\
\hline Jewish & $6(13)$ & $5(12)$ \\
\hline Buddhist & $2(4)$ & 0 \\
\hline Muslim & $1(2)$ & $1(2)$ \\
\hline Hindu & 0 & $1(2)$ \\
\hline None & $6(13)$ & $3(7)$ \\
\hline Unknown & 0 & $19(44)$ \\
\hline \multicolumn{3}{|l|}{ Employment: } \\
\hline Full time work & $12(26)$ & $13(30)$ \\
\hline Part time work & $5(11)$ & $2(5)$ \\
\hline No outside employment & $29(63)$ & $28(65)$ \\
\hline $\begin{array}{l}\text { Median (interquartile range) hours/week of direct } \\
\text { care }\end{array}$ & $28(7-168)$ & $56(8-168)$ \\
\hline Care recipients & $(n=46)$ & $(n=43)$ \\
\hline Median (range) age (years) & $83(57-99)$ & $79(50-96)$ \\
\hline Aged $<65$ years & $7(15)$ & $7(16)$ \\
\hline Female sex & $25(54)$ & $23(53)$ \\
\hline \multicolumn{3}{|l|}{ Marital status: } \\
\hline Married/living as couple & $2(4)$ & $27(63)$ \\
\hline Single & $28(61)$ & $2(5)$ \\
\hline Widowed & $15(33)$ & $11(26)$ \\
\hline Divorced & $1(2)$ & $3(7)$ \\
\hline Deceased when carer entered study & $8(17)$ & $2(5)$ \\
\hline Living with carer & $24(52)$ & $24(56)$ \\
\hline Living in care home & $12(26)$ & $14(33)$ \\
\hline \multicolumn{3}{|l|}{ Ethnicity: } \\
\hline White UK & $25(54)$ & $34(79)$ \\
\hline White other & $9(20)$ & $3(7)$ \\
\hline Black & $6(13)$ & $4(9)$ \\
\hline Asian & $3(7)$ & 0 \\
\hline Chinese & $1(2)$ & 0 \\
\hline Other & $2(4)$ & $2(5)$ \\
\hline \multicolumn{3}{|l|}{ Level of education: } \\
\hline No qualification & $22(48)$ & $20(47)$ \\
\hline Secondary & $11(24)$ & $7(16)$ \\
\hline Tertiary & $13(28)$ & $16(37)$ \\
\hline
\end{tabular}

in family carers' experience of making such decisions; however, research has so far concentrated on professionals. ${ }^{10}$ The first decision is often about obtaining a diagnosis, and this is often difficult to make, particularly in the early stages. The general practitioner may make the diagnosis or refer the patient to a specialist. Assessments include a history and mental state and cognitive tests from the person, a history from an informant, and physical investigations.

Previous studies have asked carers' views about theoretical scenarios of medical decisions at the end of life, such as whether life sustaining treatment and resuscitation should be offered. ${ }^{311}$ This study is, to our knowledge, the first to ask carers about the decisions that they have made.

Our objectives were to identify common difficult decisions made by family carers on behalf of people with dementia, to identify facilitators of and barriers to decision making in order to be able to provide appropriate care and overcome such barriers, and to use this information to assist in such decisions in future by making information available about barriers and how to overcome them in printed leaflets and online. This information is for family carers and patients and also a wider readership of doctors and other professionals from all specialties who encounter relatives and patients with these difficulties and who help them to make such decisions.

\section{METHODS}

\section{Setting}

Participants were from healthcare settings in inner and outer London. These comprised four general practices, five community clinics and three memory clinics in mental health services, and a specialist neurology dementia clinic for people with atypical or young onset dementia.

\section{Procedures}

The study had two phases: an initial focus group phase to generate a list of the most common areas in which family carers reported making difficult decisions on behalf of recipients of care, and a second phase in which these domains were discussed during in-depth individual interviews with carers who had experienced making a decision in those particular areas. In the second phase, we stopped recruiting once we had agreed that new or different subjects and perspectives were unlikely to be provided by additional participants. We recorded sociodemographic characteristics of all participants.

We used slightly different methods of identifying and approaching patients in primary and secondary care in each phase. In primary care, general practices identified people with dementia and wrote to their family carer if known to explain the study and ask if they would agree to be approached by researchers. If they wrote or phoned agreeing to this approach, we sent an information sheet.

In secondary care, one of the research clinicians wrote directly to the carers they knew who had 
Table 2 Number, relationship to care recipient, sex, and ethnicity of 46 carers taking part in topic specific individual interviews

\begin{tabular}{lccc} 
& \multicolumn{3}{c}{ Relationship } \\
\cline { 2 - 4 } Decision & $\begin{array}{c}\text { Spouses } \\
(n=22 ; 48 \%)\end{array}$ & $\begin{array}{c}\text { Children } \\
(n=19 ; 41 \%)\end{array}$ & $\begin{array}{c}\text { Other } \\
(n=5 ; 11 \%)\end{array}$ \\
$\begin{array}{l}\text { Starting health and social services for dementia: } n=30 ; 20 \\
\text { female; } 18 \text { white UK/12 BME }\end{array}$ & 15 & 13 & 2 \\
\hline Making legal decisions: $n=28 ; 21$ female; 20 white UK/8 BME & 16 & 8 & 4 \\
\hline $\begin{array}{l}\text { Deciding on care home entry: } n=22 ; 15 \text { female; } 16 \text { white UK/ } \\
\text { BME }\end{array}$ & 9 & 10 & 3 \\
\hline $\begin{array}{l}\text { Making non-dementia related medical decisions: } n=21 ; 17 \\
\text { female; } 11 \text { white UK/10 BME }\end{array}$ & 9 & 9 & 3 \\
\hline \begin{tabular}{l} 
If carer is too ill to care: $n=6 ; 4$ female; 4 white UK/2 BME \\
\hline BME=black and minority ethnic.
\end{tabular} & 4 & 1 & 1 \\
\hline
\end{tabular}

previously agreed to be approached about studies. The letter specified that unless the carer contacted the clinician's team a researcher would phone to ask if they wished to discuss the study further or take part. Alternatively, the clinician spoke to the carer during a consultation. The clinician explained the study briefly and gave an information sheet. In clinics, a DeNDroN (research network) staff member was available to explain the study further.

In all settings, a researcher phoned carers a few days after the information sheet had been sent, asking if they wanted to meet the researcher. Those who agreed to this were seen, and the study was discussed with them; those who gave informed consent then participated.

\section{Participants}

We defined a carer as an adult family member or friend who gave unpaid support for the person with dementia and who regarded themselves as a family carer. We selected for individual interviews those carers who had made decisions about the care of a person with dementia. All were currently caring or recently bereaved. To cover the range of experiences, we selected our purposive sample for people with diverse socioeconomic characteristics (sex, age, level of education, religion, and ethnicity) and those caring for people at different stages of dementia. Some were newly referred, and others had been known to services for a considerable time; we also included bereaved carers in an attempt to cover the spectrum of experiences and views. The aim of the purposive sampling was to maximise the validity of our findings by ensuring that we included carers from a range of sociodemographic groups and achieved maximum variation.

\section{Phase 1: focus groups}

We allocated participants to focus groups on the basis of shared or similar experiences, to ensure that membership remained sufficiently homogenous. The groups comprised people caring for parents (five participants), spouses (14), people now living in care homes (eight), people with young onset dementias (six), and those seen in primary care settings (10). We facilitated discussions by using a topic guide about carers' experiences, attitudes, feelings, and beliefs.

\section{Phase 2: individual interviews}

We reviewed the transcripts of focus groups to ensure that the interview schedules covered the subjects raised in focus groups relating to each decision area. We then discussed participants' personal accounts of making decisions in the five areas identified by the focus groups as most common and problematic in individual interviews by using semi-structured schedules particular to each area. Seventeen of the participants in focus groups who had made one of the decisions in question also participated in individual interviews. Interview schedules covered choices, barriers, and facilitators in decision making; cultural, religious, and spiritual beliefs and practices; and dilemmas, consequences, and advice. Interviews continued until analysis indicated that saturation of data had been achieved.

\section{Analysis}

We digitally recorded discussions and interviews, transcribed them verbatim, and removed identifying information to preserve anonymity. We used the qualitative research software programme Atlas.ti 5.2 to assist in coding, management, and analysis of data. ${ }^{12} \mathrm{We}$ sent the transcripts of individual interviews to the participants for comments and alterations. Participants reading transcripts of their interviews is considered helpful in some qualitative studies as a method of quality control and validation. Participants can ensure that the transcript is a true record of what they intended to say or, where necessary, can elaborate or provide a more nuanced perspective.

Carers all gave informed consent to the study, including recording and anonymous quotation. They have read and approved their transcripts and been given the materials with all the quotes in. We do not think that a carer could be identified, as we have deliberately given non-specific demographic information.

In both the focus group and individual interview stages, the interviews and analysis were part of an iterative process in which the study team agreed on a preliminary coding frame by using initial interviews and a broadly thematic content analytic approach. ${ }^{13}$ We analysed the focus group data to yield the full range of views on current and required provision of information. We began analysis after completing the first two focus groups and at a similarly early stage in analysis of the individual interviews. This is consistent with grounded theory techniques.

In the individual interviews, we developed our coding frame to cover the predetermined subjects and new and emergent themes. Two raters coded all data independently to ensure reliability. ${ }^{14}$ Disagreements between the raters were resolved through discussion with each other after they had completed their independent rating and by discussion with GL and CC. The team met periodically to refine the interviews in accordance with emergent themes and frame as the coding progressed ${ }^{13}$; for example, we added prompts 
about research as this was raised by interviewees. A thorough engagement with the texts and the consensus of several researchers helped to ensure that we did not end recruitment prematurely.

\section{RESULTS}

Tables 1 and 2 describe the sociodemographic characteristics of the 43 focus group participants and the 46 individual interviewees and their care recipients. As many individual interviewees had made more than one of the identified decisions, we had a total of 107 interviews covering the five decisions.

\section{Focus groups}

From the focus data, we identified five core problematic areas of decision making in dementia care and some of the factors affecting them (table 3 ).

\section{Individual interviews}

Help seeking and decision making were seldom clear cut. Participants consistently described difficulties with the responsibility of making a decision for another adult, denial and resistance by the person with memory problems, and barriers to accessing services. In circumstances in which long time roles and patterns of authority are reversed and confidences are sometimes breached, making decisions for a family member is burdened with difficulty. The ease of decision making was often determined by factors related to all the protagonists. Generally, these are the patient, the primary carer, other family members, the healthcare and social care professionals, and sometimes the voluntary sector. These relationships are not always comfortable, encompassing love, duty, and bewildered resignation. In many cases, the journey towards a decision was directed by a mixture of fatigue and a lack of obvious or available alternatives. The participants in the study related a complex, often distressing journey in negotiating an appropriate mixture of care and control within the care system.

Financial and legal decisions may be made in the context of family and professional mistrust and scepticism. Thus, in addition to service related factors, the quality of family relationships and the ensuing dynamics often determined the speed and direction of advice and support sought and the outcomes in terms of decisions made. The caring experience varied

Table $3 \mid$ Problematic areas of decision making for family members in dementia care

Decision areas Problems from carers' perspective

(1) Accessing help (how and when to access health and Refusal of help by patient; risk; confidentiality; doctor social services for dementia) denying problem

(2) Considering care home placement Timing; finances; quality of care; previous promises; perception of clash with cultural values

(3) Legal matters, including management of finances, Maintenance of autonomy; ethics; vulnerability; taking power of attorney, and continuing driving on new role

(4) Deciding on non-dementia related health care, including operations, whether to participate in research, end of life care, and resuscitation

(5) Making plans for person with dementia if carer was Burdening family; quality of care too ill to care widely in terms of the relationship of patient and carer, accommodation arrangements, and the (associated) level of formal care provided. Some of this complexity is exemplified in the following sections. The box outlines barriers to and facilitators of decision making. We illustrate below some of the complexity of decision making with reference to key issues and situations.

\section{Accessing healthcare and social care help for dementia}

Once the carer had decided to seek help, the first point of contact was usually the general practitioner, often despite opposition from the recipient of care:

"The hardest decision that I've had to make was to convince my wife there was something wrong with her, she didn't want to know ... she wouldn't talk to no one about it." (husband of early onset patient)

Carers tackled this problem in a variety of ways. Going to see the general practitioner together helped, for example, as did the doctor writing to the patient. In some case, families' strategies included manipulation, albeit benign:

"I used to [be] a bit conniving, say I'm coming to see the doctor, for me; that's the only way I could get her to the surgery, and then you start talking ... she loved the doctor." (husband of early onset patient)

\section{Professional encounters}

Once at the doctors, carers often described difficulties in obtaining the correct diagnosis, with problems either discounted or attributed incorrectly, or a reluctance to refer to specialist services. The patient's lack of insight often contributed to this, and sometimes they failed to receive a diagnosis until their relative's behaviour was very high risk:

"He was sort of in denial. . . He convinced the doctor there was nothing wrong." (wife)

"It took me about eighteen months to get [the doctor] to ... give her a test . . . later ... my daughter ... found the gas turned on and it's not alight, so ... when I left for work I had to turn the gas off, then I really pushed the doctor." (husband of early onset patient)

They commonly found that confidentiality impeded them in receiving information, but if it was clear that the care recipient gave permission then this improved:

"On the phone the people would say 'well we'd have to speak to your mother first to get permission to talk about her issues' because you know they couldn't say anything to me... I have to get my mother's permission to represent her." (daughter)

\section{Introducing services}

After carers had made a decision, they had to negotiate this with the person for whom they cared. Strategies such as introducing services a little at a time or enlisting the doctor's medical "authority" helped. If the patients still refused, this sometimes led to greater restriction:

"She wasn't washing herself, she kept saying 'no, I don't want [carers].' She [healthcare professional] said 'you can try and help slowly.' I said 'yes we will try it 
once a week.' They started a care package and it is every day now." (son)

"So long as you say ... 'doctor' in the sentence... she will go along with that, she will listen to that authority so that's been good actually." (daughter)

"He refused all help. He wouldn't let anyone come into the house, no form of carer. But then, he was wandering, a danger to himself . . . he was out all night, no idea where he had been." (wife)

\section{Information for carers}

Information was key to making decisions, but after diagnosis the quality, quantity, and timing of information about dementia provided by professional services was sometimes considered unhelpful. Carers wanted information but not all at once:

"We didn't realise what dementia meant, the implications. . . I think that people who are carers should receive some training . . . told what to expect and what to do, before it happens, not when it happens." (widower)

"I found, when he was first diagnosed, it was an awful lot to take in, you're given all this information on what you should be doing, you don't really want to know it." (wife of early onset patient)

"The advice that I would give is get as much information as possible, because information is really hard to get ... but ... is there." (wife)

\section{Decisions about care homes}

The decision that a close relative should go into a care home provoked considerable difficulties. An acknowledgment exists, albeit often tacit, that this represents a major rupture in the relationship between carer and patient. In this context, the sense of relief at care being provided is often accompanied by feelings of failure or betrayal. For example, although carers often knew that the person with dementia would never have wanted to live in a care home, as circumstances changed they felt compelled to act against this knowledge. Most families decided to keep someone at home as long as possible. The sense of guilt and failure seems to be particularly distressing for people obliged to cope alone, and although the timing and appropriateness of placement in a care home is not always agreed, carers generally found it helpful to hear the perspectives of other members of the family or professionals. This "gave permission," alleviated guilt, and re-conceptualised care homes as providing safety, either for the carer or the person with dementia, particularly if homecare services were refused. The following quotes illustrate these concerns:

"And my husband said 'promise me one thing, you'd never put me into a home,' and I said, 'I promise'." (wife)

"He has to be at the day centre six days a week ... just one day a week when he's home on Sunday, it's very difficult, so it's better than him being in a nursing home." (wife of young onset patient)
"My husband couldn't continue as he was, and he refused to have any one looking after him at home." (wife)

"And because I had ... somebody [brother] close to me saying [a care home], he could see it from a different angle to me and ... that's when I decided." (daughter)

"The GP thought that it was quite irresponsible, the idea that we should wait until my husband had an accident or something very serious happened." (wife)

"At the end of the four weeks of respite, the man in charge in the home said to me 'how can you take him home? It always needs two people to see to him.' So, after that, I decided to leave him there." (wife)

When choosing a care home, carers looked for safety, good relationships with the staff, pleasant

Barriers to and facilitators of decision making by carers

Barriers

Patient

- Denial of problem

- Rejection of help

Professional

- Not recognising problems

- Late diagnosis

- Timing and quantity of information giving

- Confidentiality and data protection

- Bureaucracy and rigidity (sticking to protocols)

\section{Psychological}

- Role conflict

- Carer guilt

- Family conflict

- Rigidity (solution fixed when circumstances change)

\section{Facilitators}

Patient

- Deference to authority

Professional

- Suggesting interventions to facilitate agreement

- Quality and timing of information

- Ensuring that the patient is asked to give permission for information to be given to carers

- Access to legal advice

Psychological-coping strategies

- Carer accompanying patient to professionals

- Social support (extended family, voluntary and community networks)

- Resources for carer (financial and social)

- Family cohesion

- Re-conceptualisation of services as optimising independence

- Allowing services to develop slowly (rather than "all or nothing")

- Knowledge of what the patient wanted when competent

- Sharing-for example, power of attorney being made for both the carer and the person with dementia 
smell, cleanliness, good atmosphere, geographical proximity to family/friends, cultural and religious identity, activities, communal areas, garden and lift access, and previous respite experiences. Many used religious and voluntary organisations to which they were connected. Carers were concerned about financial implications. Internet sites were helpful, as were voluntary sector organisations such as the Alzheimer's Society. Although these concerns added to the pressure in making decisions, carers agreed that feeling strongly involved in the decision and that it was the right thing to do was essential, as indicated by this participant:

"I think whatever you do, you've got to do it with a relatively good grace. If you feel that you've been pushed into it, or you're obliged to do it, then I think it won't work." (widow)

\section{Legal matters}

Finances were a major concern for many carers. In part, taking over their management represented a milestone in deterioration and role change and, when the patient had managed the family finances, a role reversal. Joint accounts made the logistics easier. For family carers, a pressing concern about the person's vulnerability to exploitation exists, along with a worry that they are being perceived as exploitative. However, power of attorney for financial decisions, as opposed to health and social care, seemed easier. Many participants related the importance of making decisions about wills and power of attorney when the patient retained capacity. This was sometimes recognised only with hindsight:

"I realised he couldn't, no longer sign cheques and things like that, and then we just put everything into joint, all our financial things are joint." (wife)

"The only thing that could happen now is Court of Protection ... because my wife can't sign." (husband of early onset patient)

"I made wills, my advice is to get it done sooner rather than later." (husband of early onset patient)

Various strategies were used to alleviate the difficulties. For instance, organising legal changes for the family carer, as well as the person with dementia, was often more acceptable than to do it for the person with dementia alone. Leaving manageable amounts of money for the person with dementia ensured that they retained as much financial independence and dignity as possible:

"I only did property and financial affairs - that took so long. And to have done health and welfare would have raised too many awkward questions . . . doing financial affairs fitted in with all our discussions about ... our money." (wife)

“. . . if we did [lasting power of attorney] for both of them [parents], it wouldn't feel like it was just for my mum because she's dementing." (son)

“... what I did was I opened a separate account with my name on his behalf but left his account open and every Friday $£ 30$ went into [it].” (niece)
Some people completed the forms themselves, on paper or through the internet, or with help from Age Concern, whereas most needed a solicitor to deal with the complexity:

"The best thing I. did ... was to get a good solicitor and leave it [power of attorney] to him."(widower)

\section{Driving}

Families were often able to persuade someone to stop driving, sometimes with a doctor's help, rather than reporting them to the Driver and Vehicle Licensing Agency:

"My husband was a little unhappy about the driving, but he accepted it; I think he was both unhappy and relieved." (wife)

"I was already getting worried about it [driving], we saw one of the doctors and [when I asked] he said, 'well, if he doesn't have to drive, I don't think he should' and he agreed. . . That's one of the few decisions . . . I pushed him into." (wife)

Making decisions about non-dementia related health care Several carers mentioned the need to weigh up the impact of a general anaesthetic on cognition, as well as how dementia would affect recovery:

"She has also arthritis on her knees, but ... she won't understand how to do physiotherapy ... we (sisters) discussed [the decision to have a knee replacement] ... it's not worth it." (daughter)

"She had previously been to have an extraction ... they did try [local anaesthetic] . . . she won't keep her mouth open ... she really has to have the anaesthetic. It is bad enough how she is; I don't want her to be in pain." (sister)

"We weren't in agreement with each other ... whether to have a heart operation. . . . with hindsight ... it was the right decision ... he decided ... it made his mental abilities much worse, but physically, he's much better." (wife)

\section{Non-dementia health decisions \\ End of life care and resuscitation}

Discussions about end of life care were often influenced by experiences with other people they had known with dementia or other illnesses:

"My mum was talking about when she was going to die before she even got unwell. . . I wasn't to have her resuscitated." (daughter)

"My brother-in-law fell . . . and they said to his wife 'do you want us to resuscitate him?' and she said 'I can't tell you to let him die!' So they kept him going ... he came to at one stage ... and he shook his head like that and my sister-in-law said 'I'm so sorry, I should have said to them don't resuscitate him' and I thought, 'I'm not going to let my husband suffer in that way'.' (wife)

Some talked about the helpfulness of consulting other family members, or the difficulties when they did not agree: 
"Resuscitation was the biggest decision. . . I consulted with my children and my wife's sisters and they were all in agreement . . . she has gone through enough.” (husband of young onset patient)

"My brother and sister ... wanted the drip, antibiotics and the oxygen reinstated ... and the doctor said 'it will flood her heart' and she died a horrific death ... but my brother always said, 'oh where there's hope' ... There was no hope.” (daughter)

Quality of life was important to the decision:

"I would not like my sister to be resuscitated ... she has got no quality of life ... so why put her in the same predicament and for us to be in sorrow . . . longer?' (sister)

"Mum's body ... just didn't function. . . The doctor said, 'would you like us to resuscitate,' we thought another couple of days of suffering like this, why?" (son)

At the end of life, the decision about whether instituting artificial nutrition would keep the person most comfortable was very difficult and complex:

"When it got very close to the end of [his] life, they did ask me whether I wanted him to be fed through his stomach ... the doctor ... gave me the facts and didn't try to influence me . . . but it seemed . . . that . . to prolong his life would be cruelty." (wife)

"In the last few weeks she virtually stopped eating... they ... spoon fed her ... it was all done in a very calm, serene way. I'd be against it if it was forced." (son)

"When he finally was coming home, we still had to feed him artificially through the abdomen, and . . . he was never quite the same man again." (widow)

Only one participant had made a written advanced decision (of doubtful legality, as it asked for life to be shortened):

"Both of us have written living wills . . . there are certain circumstances under which we prefer ... actually to have our life shortened ... we did give the draft ... to our GP... he told us that we had to reformulate it because . . . it has got a different name . . . advanced decisions." (wife)

\section{Taking part in research}

Carers considered the person with dementia's previous wishes when deciding about participation in research. They also considered potential benefits to the person with dementia and to others or thought that they derived personal benefit:

"I know he would volunteer partly because ... he did [participate in research]." (wife)

"When we talked about donating organs before [he] got ill, he'd always said he didn't want it . . . so it was quite simple." (wife of young onset patient)

"If they ever came out with a drug I don't mind . . . making that decision for my sister to be given a chance." (sister)

"I really wanted to be part of the research, because my own experience... was horrible, anything that can be done to stop other people having that same experience ... has to be worthwhile." (daughter)
"... having the assessment through the research was very useful . . . one learns a little also because . . . you don't realise sometimes how you are feeling." (widow)

\section{Plans for future if carer was too ill to care}

Several carers had made plans for the care of the person with dementia if they were no longer able to provide care, whereas others thought that things should be sorted out as they happened:

"What if something happened to me? ... I've even spoken to my children about that ... they would not be responsible for their dad, they'd be there for him, but other arrangements would be made for his care. I've set everything out... I want to make things easy for my two children."(wife)

"You have to decide [everything]; and it's not a matter of it being easy, or not easy, you just have to do it because that's the practicalities of life." (wife of young onset patient)

"When I read and see things about how people go through . . . that is a bit worrying. But then I decided I will just take each day as it comes. You can't look too far in the future." (wife)

\section{DISCUSSION}

Family carers of people with dementia have to make difficult decisions throughout the course of dementia from onset until the end of life. This is the first study to ask a purposively sampled, diverse range of people caring for someone with dementia what were the most difficult decisions and what were the barriers and solutions. Participants consistently described particular problems, emphasising the resistance of the person with dementia and changing their long time family role. They became a patient manager, while remaining a family member. Even with the legal authority to make and enforce decisions for the person without capacity, in practice families nearly always need to gain agreement to ensure that the person with dementia retains dignity. To acquire a diagnosis or a referral for diagnosis, for example, carers had to make the transition from seeing their relative as an autonomous adult to being their spokesperson. Family cohesion alleviated emotional conflicts and facilitated decisions, as did professionals' support, information sharing, and use of their "authority" to advocate helpful interventions. Carers emphasised the practical and emotional importance of the fresh perspective of other family members and support from professionals and voluntary organisations in making decisions. Some carers had found sources of support and information, but others had not. Many of the carers said that this was the first time they had had the opportunity to discuss the difficulties around making decisions; they valued this and questioned why they had not been offered it earlier. Problems were aggravated by carers' role conflict and guilt. Family disagreements compounded decision making difficulties. This was particularly evident in end of life decision making, when the need for decisions to be unanimous was, perhaps, particularly strong. Those who opted for the more life prolonging 


\section{WHAT IS ALREADY KNOWN ON THIS TOPIC}

A large and increasing number of family carers make proxy decisions for relatives or friends with dementia

They find this distressing, and barriers to making such decisions include lack of information and emotional support

Better information faciltiates such decisions

\section{WHAT THIS STUDY ADDS}

Difficulties in decision making for people without capacity are often aggravated by their active resistance

Legal authority is not enough; families had to devise strategies to overcome barriers and to gain agreement

Support for carers to make these decisions is important; the strategies from this study will be made available to carers and professionals

treatment seemed to be more likely to express regret. Only one person cared for someone with dementia who had made an advance directive, and circumstances had not occurred in which it could be used.

\section{Strengths and weaknesses of study}

Our carers came from a wide range of settings and sociodemographic backgrounds, and we achieved theoretical saturation. All those who took part in the research were willing to do so, lived in a city, recognised that their relative had dementia, and for the purposes of our study were willing to define themselves as family carers. Most of the participants were known to secondary care. Thus, we may have missed people who did not see themselves as carers or whose relative had not received a diagnosis. Nevertheless, some of the participants had originally not accepted that their relative had dementia, or their relative had refused to go to doctors, and some were known only to primary care. We did not make any assessment of the patients' ability to make the decisions the carers mentioned, and some may not have lacked capacity in the situation specified. All of the people with dementia were at least 50 years old. Their respect for doctors' authority may be a generational effect, and attitudes may be different in decades to come. Younger carers (five were in their 30s), however, also emphasised how professionals' authority helped emotionally as well as practically. Carers and people with dementia may have differing views about difficulties and what to do in a given situation, and this is not always related to the dementia. They may have separate interests, or their views may have diverged. ${ }^{15}$

\section{Comparison with other studies}

Other studies have, like ours, found that many patients are not diagnosed as having dementia until late in the illness, often at a time when a crisis occurs, which could have been avoided with earlier diagnosis and inter vention. ${ }^{16}$ Late diagnosis often comes too late for the person with dementia to be able to make most choices; earlier diagnosis and management of dementia facilitates patients' choice and improves the quality of life of the person with dementia and their relatives, as well as being cost effective. ${ }^{16}$

Our study adds some strategies to facilitate such diagnosis. In common with a recent ethical report, we found that doctors have an important role as either barriers or facilitators and should, for example, actively encourage the person with dementia to allow sharing of information with family carers. ${ }^{15}$ Professionals should deliver information in chunks, as carers valued information but, as in previous studies, found it overwhelming if given all together at diagnosis. ${ }^{17}$ As in previous studies, interviewees found that professionals' views and advice reduced guilt. ${ }^{15}$

\section{Clinical and policy implications}

Supporting carers to make decisions is an important and urgent next step. We have, therefore, devised a series of factsheets covering barriers and facilitators for family carers based on the findings of this study and covering these key decisions, including carers' experiences in their own words and with a summary "Things to think about" section. These set out the strategies that enabled carers to cope. Providing information for carers is a critical component of high quality dementia care, but carers do not want it all at once. ${ }^{17}$ We have therefore designed our factsheets so that carers can be provided with information currently relevant to them or that they would like to think about. These are available on bmj.com, and we are also planning to make them available in non-clinical settings, as they discuss accessing help and should therefore be useful before diagnosis.

We recommend several important strategies to help to overcome the difficulties described (summarised in the box). Professionals can recommend the following successful strategies to aid the implementation of most decisions: introducing change slowly, organising legal changes for the family carer as well as the person with dementia, and involving a professional to persuade the person with dementia to accept services and emphasising that services optimise rather than impede independence. When dealing with services, carers often needed to ask for what they felt was needed rather than waiting for it to be offered.

To access diagnosis and care, the carer can make appointments with the general practitioner, accompany the patient to the surgery, point out symptoms, gain permission to receive confidential information, ask for a referral to specialist services, and use the professionals' authority to persuade the patient to agree to this.

People found decisions around end of life care very difficult. They were helped by knowing the views that the person with dementia held before losing capacity about what they would want in this situation, as well as by clear prognostic information, knowledge about future quality of life, and family support.

Services need to be appropriate for age and culture. Many people referred to their own ethnic or family culture as being one in which, for example, people would not use care homes. Carers often wanted a 
care home or day centre specific to their beliefs and cultures, so their relative would feel more at home. Similarly, they made decisions about end of life care on the basis of the person's previous wishes, religious views, and quality of life.

Although considering previous discussions with the person with dementia to understand their wishes was often helpful, carers found that circumstances changed. For example, the decision never to allow a relative to move to a care home was revised because of unacceptable risks if they continued to live at home. They then needed to make decisions that had previously been unthinkable, and they often felt guilty.

\section{Unanswered questions and future research}

We have identified that family conflict makes decisions more difficult, but family counselling has not previously been found to be of benefit for carers and future research should perhaps concentrate on using specific coping strategies that have previously helped carers to manage. ${ }^{18}$ Although we hypothesised before collecting the data that we would find ethno-cultural differences related to help seeking, in fact such differences were minor and mainly reflected dietary and language choices. Although social class differences may exist, they did not emerge strongly from the data.

Our study raises several unanswered questions. Should all doctors routinely be asking patients whether they can discuss their medical details with their closest relative in all circumstances or in specified circumstances in the future? Our family carers often did not think that they had been informed or understood what might happen if an attempt was made to resuscitate someone with advanced dementia. How can this be communicated better? Although we have produced leaflets to help with the concerns that were raised by relatives, the impact of the leaflets has yet to be evaluated in real life. We do not know whether they will help if delivered by themselves or if they need to be delivered by a professional who can provide the back-up care and help carers to access the services suggested. Further work should evaluate this.

We thank the carers who gave us their time and talked of their experiences; North Thames DeNDRoN, PCRN-GL, and clinicians in Camden and Islington NHS Foundation Trust, Barnet, Enfield and Haringey Mental Health Trust, Camden Primary Care Trust, and the Dementia Research Centre, UCLH, for helping to identify participants; the Alzheimer's Society Islington for helping us to design the study; and Camden and Islington NHS Foundation Trust for allowing us to use Camden Mews day hospital as the venue for the focus groups. Contributors: GLivingston, CC, GLeavey, S Nurock, ES, and GR contributed to the design of the study. GL, ES, K Judd, DL, and SB identified the participants. GLivingston, GLeavey, CC, ES, and GR facilitated the focus groups. MM, DL, SB, KS, and R Li did the individual interviews. DL, MM, $\mathrm{SB}$, and $\mathrm{KS}$ analysed the data for themes and, with GLivingston and CC agreed on a coding frame. All authors contributed substantially to conception and design, or analysis and interpretation of data, and to drafting the article or revising it critically for important intellectua content. GLivingston is the guarantor.

Funding: The study was funded by BUPA Foundation, which had no role in the study design; the collection, analysis, and interpretation of data; or the writing of the article and the decision to submit it for publication. All the researchers are independent of the funders.

Competing interests: All authors have completed the Unified Competing Interest form at www.icmje.org/coi_disclosure.pdf (available on request from the corresponding author) and declare that GLivingston, GLeavey, $G R$, and CC have support from BUPA Foundation for the submitted work; (2) SB, KS, DL, and MM have no relationships with companies that might have an interest in the submitted work in the previous 3 years; (3) their spouses, partners, or children have no financial relationships that may be relevant to the submitted work; and (4) all authors have no non-financial interests that may be relevant to the submitted work.

Ethical approval: The relevant research ethics and research and development committees approved the study. Participating family carers gave signed informed consent.

Data sharing: No additional data available.

1 Ferri CP, Prince M, Brayne C, Brodaty H, Fratiglioni L, Ganguli M, et al. Global prevalence of dementia: a Delphi consensus study. Lancet 2005;366:2112-7.

2 Hirschman K, Kapo J, Karlawish J. Why doesn't a family member of a person with advanced dementia use a substituted judgment when making a decision for that person? Am J Geriatr Psychiatry 2006;14:659-67.

3 Mezey M, Kluger M, Maislin G, Mittelman M. Life sustaining treatment decisions by spouses of patients with Alzheimer's disease. J Am Geriatr Soc 1996;44:144-50.

4 Davies S, Nolan MR. 'Making the best of things': relatives' experiences of decisions about care-home entry. Ageing Soc 2003;23:429-50.

5 Alzheimer Research Forum. AD research participation: informed consent complicates trials, part 1. 2008. www.alzforum.org/new/ detail.asp?id=1867.

6 Butcher HK, Holkup PA, Park M, Maas M. Thematic analysis of the experience of making a decision to place a family member with Alzheimer's disease in a special care unit. Res Nurs Health 2001;24:470-80.

7 Wackerbarth S. The Alzheimer's family caregiver as decision maker: a typology of decision styles. Gerontologist 2002;42:340.

8 Hansen L, Archbold PG, Stewart BJ. Role strain and ease in decisionmaking to withdraw or withhold life support for elderly relatives. Nurs Scholarsh 2004;36:233-8.

9 Department of Health. The Mental Capacity Act 2005. 2005. www. opsi.gov.uk/acts/acts2005/ukpga_20050009 en_1.

10 Shah AK, Heginbotham C, Fulford B, Banner N. The application of the Mental Capacity Act 2005 among geriatric psychiatry patients: a pilot study. Int Psychogeriatr 2009;5:922-30.

11 Potkins D, Bradley S, Shrimanker J, O’Brien J, Swann A, Ballard C. End of life treatment decisions in people with dementia: carers' views and the factors which influence them. Int J Geriatr Psychiatry 2000;15:1005-8.

12 Coffey A, Attkinson P. Making sense of qualitative data; complementary research strategies. Sage, 1996.

13 Miles MB, Huberman AM. Qualitative data analysis: an expanded sourcebook. 2nd ed. Sage, 1994.

14 Smith JA. Beyond the divide between cognition and discourse: using interpretative phenomenological analysis in health psychology. Psychology and Health 1996;11:261-71.

15 Nuffield Council on Bioethics. Dementia: ethical issues. Nuffield Council on Bioethics, 2009.

16 Department of Health. Living well with dementia: a national dementia strategy. DH, 2009.

17 Wald C, Fahy M, Livingston G, Walker Z. What to tell dementia caregivers-the rule of threes. Int J Geriatr Psychiatry 2003;18:313-7.

18 Selwood A, Katona C, Lyketsos C, Johnston K, Livingston G. A systematic review of the effect of psychological approaches to family caregivers of people with dementia. J Affect Disord 2007;101:75-89.

Accepted: 10 June 2010 